\title{
Recent Achievements in Enantioselective Borrowing Hydrogen by the Combination of Iron- and Organocatalysis
}

\author{
Mylène Roudier, Thierry Constantieux, Jean Rodriguez, and Adrien Quintard*
}

\begin{abstract}
This article summarizes our recent developments in allylic alcohol functionalization by the interconnection of two catalytic cycles. By combining an iron-catalyzed borrowing hydrogen with an organocatalytic enantioselective nucleophilic addition, allylic alcohols can be converted to enantioenriched chiral aliphatic alcohols in up to $92 \%$ ee. This eco-compatible one-operation multi-catalytic process allows the classical oxidation-addition-reduction steps usually required for this transformation to be bypassed. Synthetic applications in the synthesis of different fragments of some important natural products have highlighted the great potential of this transformation.
\end{abstract}

Keywords: Borrowing hydrogen · Enantioselective synthesis · Iron catalysis · Organocatalysis

\section{Introduction}

In a world where a decrease in hydrocarbon consumption becomes an urgent necessity, our challenge as chemists is to continuously discover innovative approaches towards greener complex molecule synthesis. Ideally, complex molecular frameworks should be constructed in one single operation from simple substrates without generating any waste. ${ }^{[1]}$ Catalytic reactions are one of the solutions towards this goal, however, one single catalytic activation mode taken alone might in some cases be insufficient for the appropriate activation of simple non-activated starting materials. This is notably the case for several organocatalytic activation modes such as aminocatalysis where highly reactive carbonyl compounds such as aldehydes are required for the catalytic activity. ${ }^{[2]}$ The relatively poor stability of aldehydes and their usual generation by means of stoichiometric oxidants considerably limit the eco-compatibility of the developed synthetic methodologies. ${ }^{[3]}$ In addition, if an alcohol is required in the final product, an additional reduction is needed leading to a three-step sequence to go from the starting alcohol to the final chiral one (Scheme 1a).

To go beyond current knowledge on enantioselective synthesis and notably on organocatalytic reactions, our research activity is focused on the combination of multiple catalytic species, notably metals and organocatalysts. ${ }^{[4]}$ Indeed, appropriately combining different catalytic activation modes with orthogonal reactivity should allow the implementation of the organic chemistry toolbox with processes able to go from what are currently believed to be unreactive simple substrates to complex architectures. Thanks to such an approach, we believe that a multi-catalytic system would allow the classical use of carbonyl compounds in aminocatalytic reactions to be bypassed. In addition to allowing the discovery of innovative reactivity, it should also result in global waste reduction, a crucial aspect for sustainable chemistry. Our initial goal was to focus on the combination of borrowing hydrogen or hydrogen auto-transfer with enantioselective

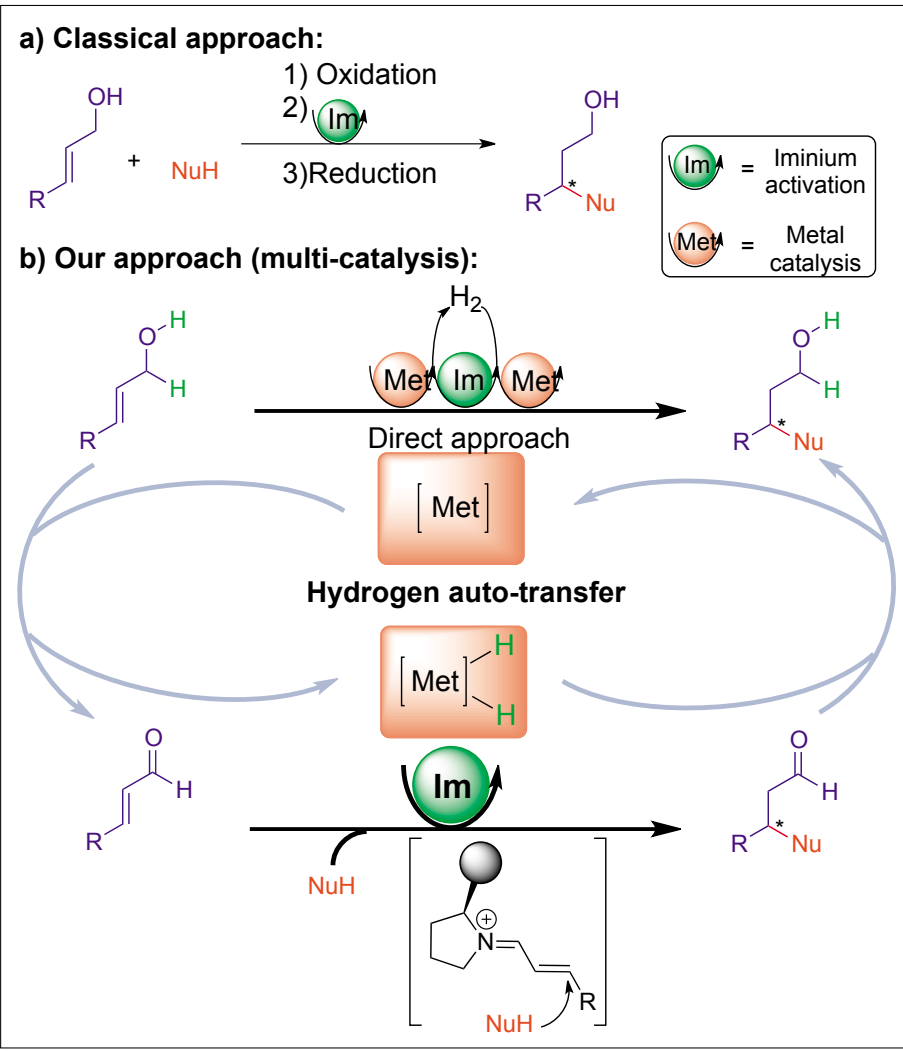

Scheme 1. Concept of the multi-catalytic borrowing hydrogenorganocatalysis. 
organocatalytic reactions. Indeed, borrowing hydrogen is a powerful method to activate in a transient manner an alcohol into a carbonyl function thanks to an appropriate metal complex. ${ }^{[5]}$ After transformation into another active chemical function, hydrogen back transfer from the metal generates the final product with the same oxidation state as the one of the starting materials. One of the most famous examples of this type of reactivity is alcohol direct amination. ${ }^{[5]}$ This strategy firstly avoids the isolation of unstable aldehydes but in addition considerably limits waste generation since no stoichiometric oxidants or reductants are required.

Despite considerable efforts in the development of hydrogen auto-transfer transformations, the enantioselective variant was largely underdeveloped when we initiated our research program. ${ }^{[6]}$ Our idea was to combine in a relay multi-catalytic cycle a borrowing hydrogen together with an enantioselective organocatalytic transformation, here an iminium catalytic transformation (Scheme 1b). ${ }^{[7]}$ Starting from an allylic alcohol, a metal complex would perform the selective dehydrogenation providing the transient catalytically generated $\alpha, \beta$ unsaturated aldehyde. This species would react in an enantioselective iminium activation mode triggering the formation of the chiral aliphatic aldehyde. Final hydrogen back transfer would directly provide the final saturated chiral alcohol. Key to the success of the planned transformation was our ability to find an hydrogen transfer complex: i) able to selectively dehydrogenate allylic alcohols and transfer back again hydrogen to aliphatic aldehydes; ii) compatible in the presence of secondary amines organocatalysts; iii) efficient at temperatures where enantioselective reactions could take place (typically below $40{ }^{\circ} \mathrm{C}$ ). Besides the discovery of an appropriate metal complex, an additional challenge was the selection of an organocatalytic transformation efficient in the presence of an $\alpha, \beta$-unsaturated aldehyde generated in only a catalytic amount (at the best equal to the metal complex loading).

In the present article, we summarize our recent efforts at developing such a challenging multi-catalytic borrowing hydrogen functionalization of allylic alcohols.

\section{Development of the First Amine-Iron Allylic Alcohol Functionalization}

Given the known propensity of metal complexes to promote allylic alcohols isomerization instead of dehydrogenation, we first focused on the identification of a suitable dehydrogenation metal complex for our transformation. After intensive efforts, we discovered that easily available iron pre-catalyst $[\mathbf{F e}]^{[8]}$ was able to selectively dehydrogenate cinnamyl alcohol in the presence of diaryl-prolinol silyl ethers Cat1 or Cat 2 and under mild conditions (Scheme 2). Indeed, at room temperature, we observed in the presence of $10 \mathrm{~mol} \%$ of [Fe], the clean formation of around $10 \%$ of cinnamaldehyde corresponding to the oxidation by one molecule of iron catalyst. Here, the use of catalytic $\mathrm{Me}_{3} \mathrm{NO}$ is crucial to form the active iron catalytic complex $\mathbf{A}$ by decoordination of one $\mathrm{CO}$ from [Fe]. ${ }^{[8]}$ Complex $\mathbf{A}$ is able to abstract one molecule of hydrogen from the alcohol, forming $\mathbf{B}$ (a complex able to reduce aldehydes) and one molecule of aldehyde. With the identification of a suitable mutually compatible catalytic species, we subsequently focused on the identification of appropriate nucleophiles.

Gratifyingly, ketoesters $\mathbf{3}$ as pro-nucleophiles did promote the subsequent nucleophilic addition triggering the final step of our catalytic cycle, namely the final hydrogen back transfer directly leading to the alcohol 4-13 (Scheme 3). [9] These alcohols are obtained in an equilibrium between the open (4o-13o) and closed (4c-13c) lactol forms. Reaction optimization revealed that depending on the substrates, 6.5 to 10 mol\% of iron complex could be used while reaction could occur from room temperature to $0{ }^{\circ} \mathrm{C}$, a less common temperature for a borrowing hydrogen.

The reactivity of iron complex [Fe] is really notable since it allows the resolution of most challenges associated with our designed process. Indeed, it is selective for allylic alcohol dehydrogenation under mild conditions, it does not interfere in the nucleophilic addition and it is selective for the final aldehyde reduction with limited hydrogen transfer to the ketone of the ketoester.

Using the combination of [Fe] and
Cat1, a variety of cyclic or acyclic ketoesters smoothly react with different allylic alcohols providing a broad range of chiral alcohols 4-13 under mild conditions (Scheme 3). The enantiomeric excesses ranged from 79 to $90 \%$ ee while in some cases, up to three contiguous stereocenters were controlled in >9:1 dr. The diastereocontrol on products 4-7 directly arises from the transition state of the Michael addition while for acyclic starting ketoesters, the diastereocontrol on 8-12 might come from a thermodynamic equilibrium. On the allylic alcohol, various substitution patterns such as alkyl chains (Me, $n$-Pr) as well as aromatic substituents are also well tolerated.

Preliminary mechanistic investigations have shown that each catalyst is performing its own specific task in the process. The iron complex exclusively performs the hydrogen transfer while the organocatalyst is the single catalytic species involved in the nucleophilic addition.

\section{Extension of the Multi-catalytic Activation to Innovative Cascades}

Protected 3-alkylpentanol structures 15 (Scheme 4) are widely applied in natural product synthesis but require lengthy procedures for their preparation with several redox operations as well as protecting group manipulations. The lack of eco-compatible methods for their preparation constituted for us an opportunity to demonstrate the power of our approach to rapidly assemble these crucial fragments.

As mentioned above, the chiral alcohols 40 obtained after addition of ketoesters to allylic alcohols are in equilibrium with the closed lactol form $\mathbf{4 c}$ (Scheme 4). This interesting behaviour led us to wonder if the developed process could be combined with a cascade involving a retro-Claisen fragmentation. This sequence takes ad-

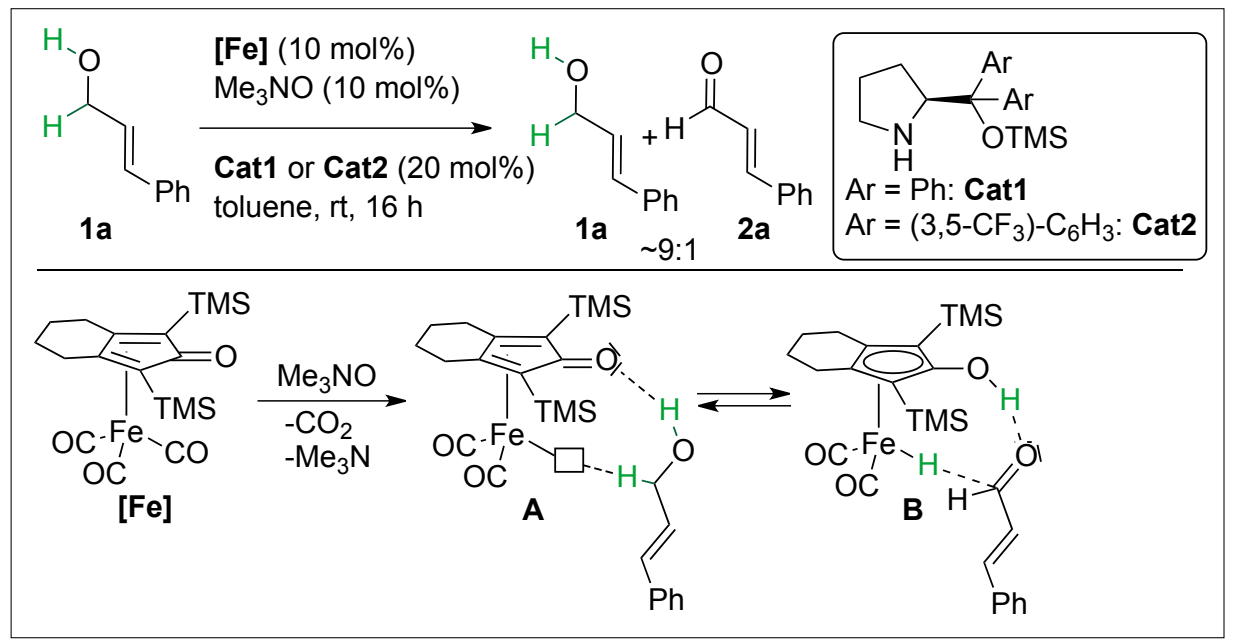

Scheme 2. Compatibility and selectivity of [Fe]. 


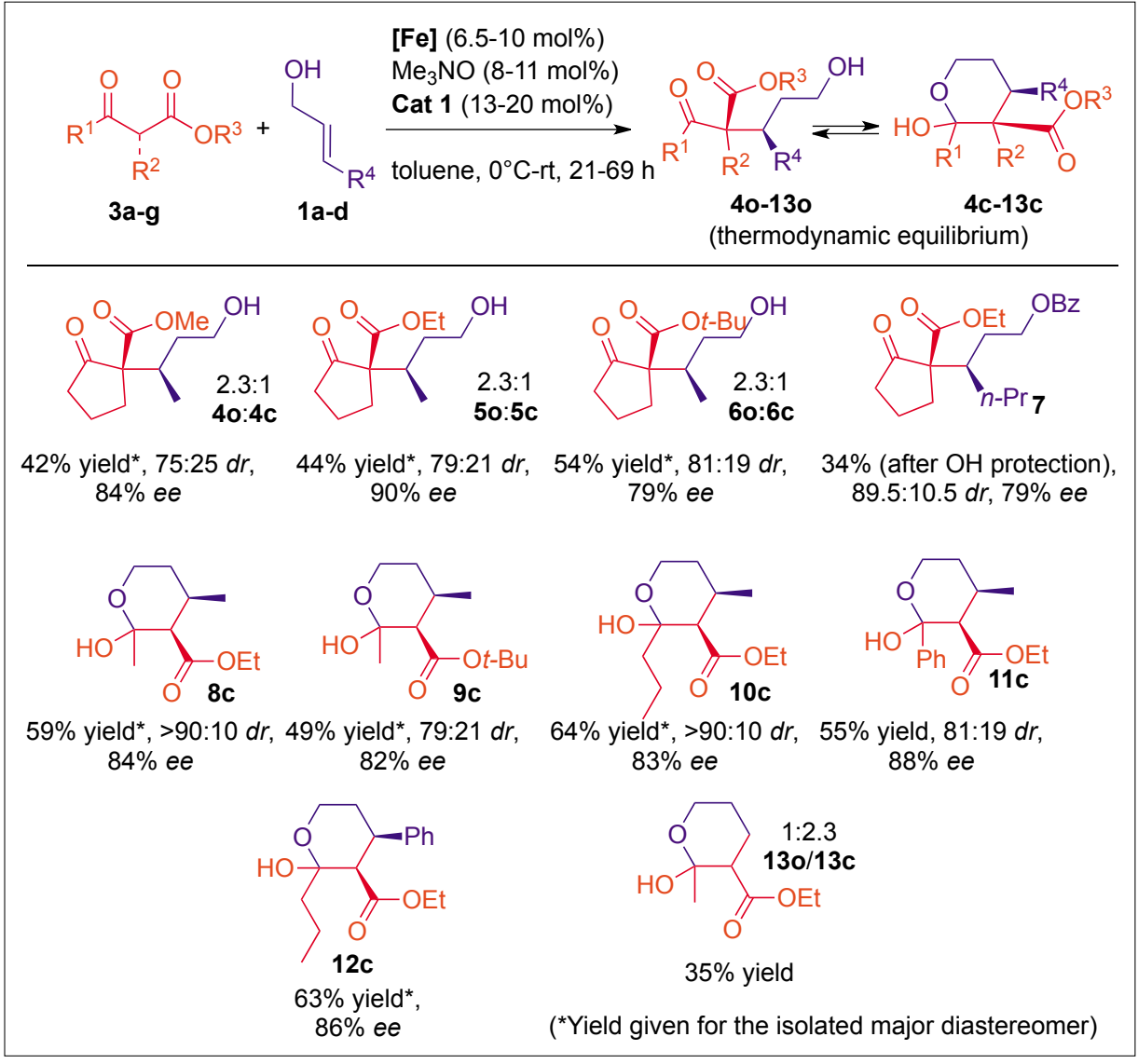

Scheme 3. Scope of the enantioselective iron-amine catalysis using keto-esters.

vantage of the activation provided by one of the non-innocent electron-withdrawing groups in 14, which also serves as a transferable function to the primary alcohol liberating a mono-activated substrate such as a mono-ketone together with the corresponding protected alcohol $\mathbf{1 5}$ (Scheme 4).

Since no retro-Claisen fragmentation was observed while using ketoesters, we decided to modulate the electron-withdrawing character of the substituents on the pro-nucleophile to try to push forward this fragmentation. Gratifyingly, using more electron-withdrawing diketones $\mathbf{1 4}$, a clean cascade occurred directly providing the expected final rearranged products 15a-q (Scheme 5). ${ }^{[10]}$ Under optimized conditions, structurally diverse cascade chiral products could be obtained under enantiocontrol ranging from 40 to $92 \%$ $e e$. Depending on the substrate used, either Cat1 or Cat2 had to be used while no explanation has been found so far for the differences observed between those two catalysts. Acyclic as well as cyclic diketones worked equally well in this process, even though using cyclic diketones, products with two adjacent stereocen- ters $15 \mathbf{e}-\mathbf{g}$ were obtained with moderate diastereocontrol. These results can be explained by the low diastereoselectivity of the final reprotonation creating the second stereocenter at the end of the retro-Claisen fragmentation. Concerning the allylic alcohols, generally, crotyl alcohol (methyl substituent) gave the best results while increasing the chain length decreased the enantioselectivity (Scheme 5). Finally, starting from acyclic disymmetrical diketones, rearrangement priority depends on the stereochemistry of the substituents on the ketones. Indeed, compounds $\mathbf{1 5} \mathbf{j}$ and $\mathbf{1 5} \mathbf{k}$ are obtained in an approximate $2: 1$ ratio from the same diketone, indicating that the small acetyl group migrates more favorably than the bulkier cyclohexanecarbonyl group. In the case of tertiary $v s$ primary carbon substituents on the ketone, perfect selectivity is observed in favor of acetyl migration (15i and 15l). Finally, it is important to note that $\mathrm{Me}_{3} \mathrm{NO} \cdot 2 \mathrm{H}_{2} \mathrm{O}$ is used in this reaction, highlighting the water tolerance of the multi-catalytic system.

\section{Synthetic Applications}

As already mentioned, 3-alkylpentanols have been widely applied in the synthesis of biologically active natural products. In order to demonstrate the efficiency of the developed cascade, we undertook several derivatizations of the obtained products to a commercial odorant molecule or natural product fragments (Scheme 6). Reducing both ester and ketone of 15a followed by diastereoselective acid catalyzed cyclization provided in only three steps from commercial products, the most odorant isomer of Doremox ${ }^{\circledR}$ (Scheme 6a). ${ }^{[11]}$ From 15b, obtained from acetylacetone and crotyl alcohol in 94\% yield and $80 \%$ $e e$, protecting group interconversion provided 17, a known fragment en route to lyconadin A (Scheme 6b). ${ }^{[12]}$ This frag-

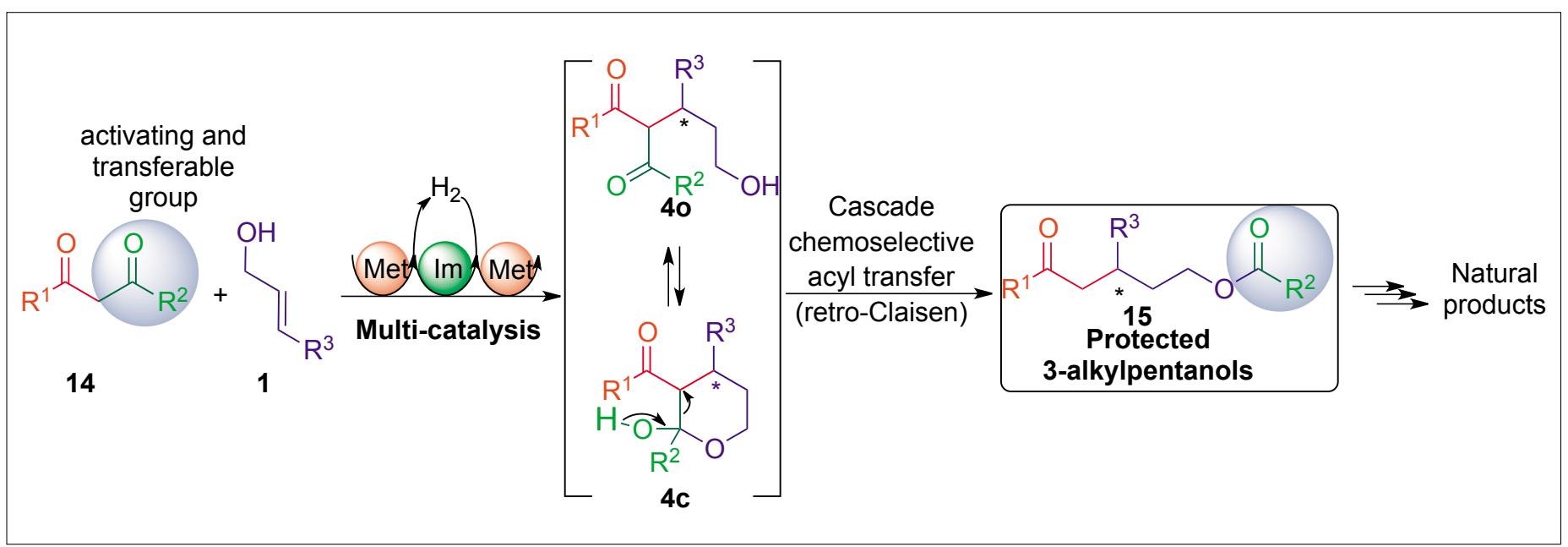

Scheme 4. Projected redox-neutral cascade synthesis of protected 3-alkylpentanols. 


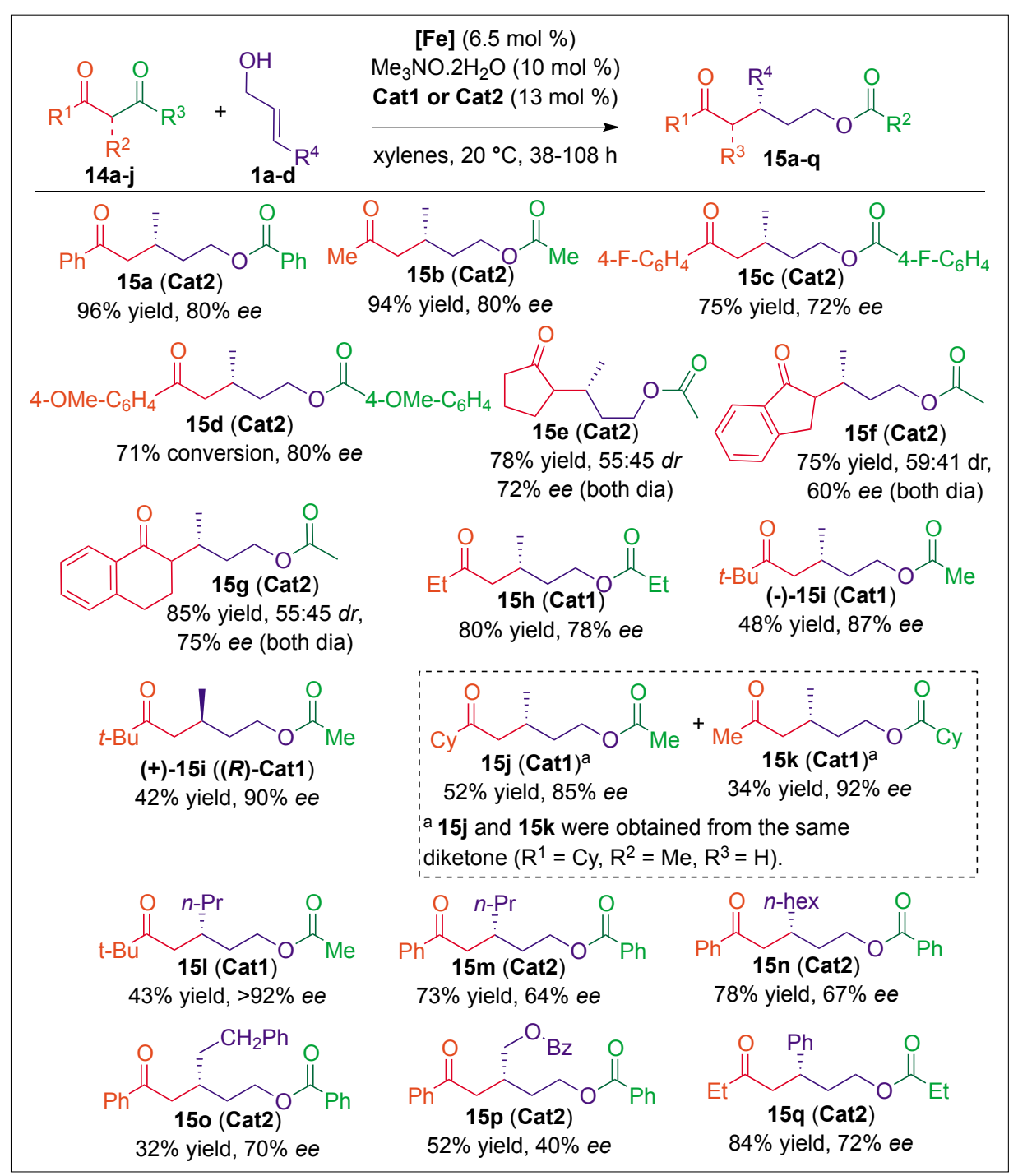

Scheme 5. Scope of the cascade allylic alcohol functionalization-retro Claisen cascade.

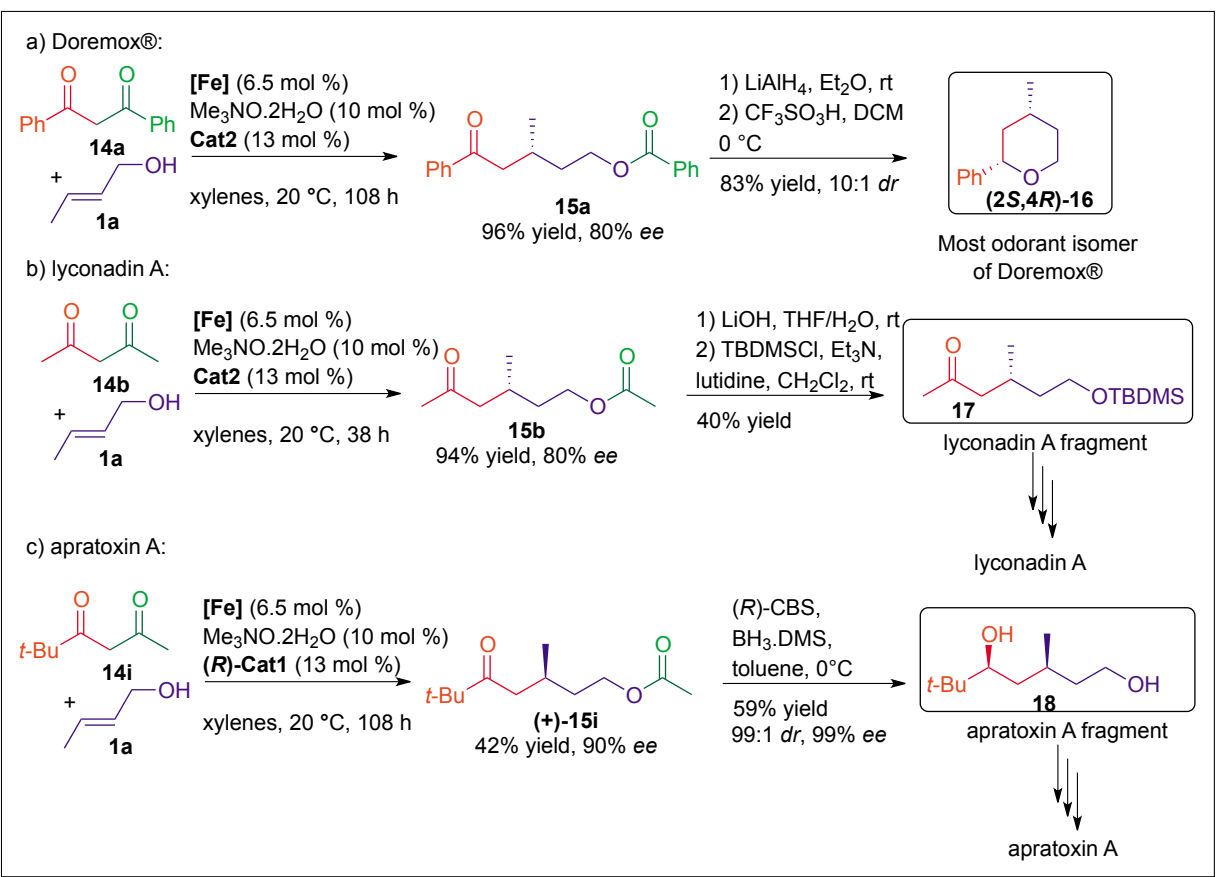

Scheme 6. Synthetic applications of the cascade. ment previously required six steps for its preparation. Finally, diastereoselective reduction of (+)-15i obtained in $42 \%$ yield and $90 \%$ ee from $\mathbf{1 4 i}$ and crotyl alcohol, directly provided upon aqueous work-up diol 18, another known fragment used in the synthesis of apratoxin A (Scheme 6c). ${ }^{[13]}$ The synthetic route applied in the literature to access this compound previously required 5 to 11 steps. All these examples, considerably short-cutting known synthetic sequences to access crucial molecular fragments, highlight the synthetic potential of the above developed cascade.

\section{Conclusion}

This article summarizes our recent efforts in the development of eco-compatible functionalization of allylic alcohols. Thanks to an adequate cooperation between an iron-based borrowing hydrogen catalyst and an organocatalyst, the redox neutral addition of ketoesters and diketones to these alcohols is possible in enantioselectivities up to $92 \%$ ee. Subsequent cascade by retro-Claisen fragmentation allows the simple preparation of valuable synthetic building blocks and should find numerous additional applications in the construction of complex molecular scaffolds. Our future efforts will focus on the expansion of this chemistry to other redoxneutral reactions. Preliminary mechanistic investigations have confirmed the nature of the combined catalytic cycles (borrowing hydrogen and organocatalytic nucleophilic addition). Further mechanistic investigations notably on the kinetics of both cycles should further help understand the reaction behaviour and improve the efficiency of the catalytic systems.

\section{Acknowledgements}

The Agence Nationale pour la Recherche (ANR-13-PDOC-0007-01), the Centre National de la Recherche Scientifique (CNRS) and the Aix-Marseille Université are gratefully acknowledged for financial support. The authors warmly thank Marion Jean and Nicolas Vanthuyne (Aix-Marseille Université) for chiral-phase HPLC analysis of some chiral compounds.

Received: March 12, 2015

[1] a) J. B. Hendrickson, J. Am Chem Soc 1975 97, 5784; b) B. M. Trost, Science 1991, 254, 1471 ; c) P. A. Wender, B. L. Miller, Nature 2009, 460, 197; d) T. Gaich, P. S. Baran, J. Org. Chem. 2010, 75, 4657.

[2] a) S. Bertelsen, K. A. Jørgensen, Chem. Soc. Rev. 2009, 38, 2178; b) P. Melchiorre, M. Marigo, A. Carlone, G. Bartoli, Angew. Chem. Int. Ed. 2008, 47, 6138.

[3] For selected examples of in situ generation of aldehydes for aminocatalytic reactions: a) P. A. Slatford, M. K. Whittlesey, J. M. J. Williams, Tetrahedron Lett. 2006, 47, 6787; b) O. Abillard, 
B. Breit, Adv. Synth. Catal. 2007, 349, 1891; c) S. Chercheja, P. Eilbracht, Adv. Synth. Catal. 2007, 349, 1897; d) A. Quintard, A. Alexakis, C. Mazet, Angew. Chem. Int. Ed. 2011, 50, 2354 e) f) M. Rueping, H. Sundén, L. Hubener, E. Sugiono, Chem. Commun. 2012, 48, 2201; f) M. Rueping, H. Sundén, E. Sugiono, Chem. Eur. J. 2012, 18, 3649; g) M. Rueping, J. Dufour, M. S. Maji, Chem. Commun. 2012, 48, 3406; h) P. Hermange, F. Portalier, C. Thomassigny, C. Greck, Tetrahedron Lett. 2013, 54, 1052.

[4] For recent reviews on dual organocatalysis see: a) A. E. Allen, D. W. C. MacMillan, Chem $S c i$ 2012, 3, 633; b) Z. Du, Z. Shao, Chem. Soc. Rev. 2013, 42, 1337.; c) For one of our recent achievements in the field see: A. Quintard, J. Rodriguez, Chem. Commun. 2015, 51, 9523.

[5] For selected reviews on borrowing hydrogen: a) M. H. S. A. Hamid, P. A. Slatford, J. M. J. Williams, Adv. Synth. Catal. 2007, 349, 1555; b) G. E. Dobereiner, R. H. Crabtree, Chem. Rev. 2010, 110, 681; c) C. Gunanathan, D. Milstein, Science 2013, 341, 6143; d) A. Quintard, T. Constantieux, ChemSusChem. 2016, 9, 28.
[6] For a recent highlight on the problematic: a) D. Hollmann, ChemSusChem 2014, 7, 2411. For examples of enantioselective borrowing hydrogen: b) D. J. Shermer, P. A. Slatford, D. D. Edney, J. M. J. Williams, Tetrahedron: Asymm. 2007, 18, 2845; c) F. E. Putra, Y. Oe, T. Ohta, Eur. J. Org. Chem. 2013, 6146; d) O O. Kovalenko, H. Lundberg, D. Hübner, H Adolfsson, Eur. J. Org. Chem. 2014, 6639; e) Y. Zhang, C-S. Lim, D. S. Boon Sim, H-J. Pan, Y. Zhao, Angew. Chem. Int. Ed. 2014, 53, 1399.

[7] For a previous example of allylic alcohols functionalization by hydrogen autotransfer and Lewis acid catalyzed addition: b) P. J. Black, W Harris, J. M. J. Williams, Angew. Chem. Int. Ed. 2001, 40, 4475.

[8] For a review on [Fe]: a) A. Quintard, J Rodriguez, Angew. Chem. Int. Ed. 2014, 53, 4044. For selected examples of application of [Fe]: b) H-J. Knölker, J. Heber, C. H. Mahler, Synlett 1992, 1002; c) H.-J. Knölker, E. Baum, H. Goesmann, R. Klauss, Angew. Chem. Int Ed. 1999, 38, 2064; d) C. P. Casey, H. Guan, J. Am. Chem. Soc. 2007, 129, 5816; e) M. K.
Thorson, K. L. Klinkel, J. Wang, T. J. Williams, Eur. J. Inorg. Chem. 2009, 295; f) S. A. Moyer, T. Funk, Tetrahedron Lett. 2010, 51, 5430; g) M. G. Coleman, A. N. Brown, B. A. Bolton, H. Guan, Adv. Synth. Catal. 2010, 352, 967; h) S. Zhou, S. Fleischer, K. Junge, M. Beller, Angew. Chem. Int. Ed. 2011, 50, 5120-5124; i) T. Yan, B. L. Feringua, K. Barta, Nature Commun. 2014, 5, 5602 .

[9] A. Quintard, T. Constantieux, J. Rodriguez, Angew. Chem. Int. Ed. 2013, 52, 12883.

[10] a) M. Roudier, T. Constantieux, A. Quintard, J. Rodriguez, Org. Lett. 2014, 16, 2802; b) M. Roudier, T. Constantieux, A. Quintard, J. Rodriguez, Eur. J. Org. Chem. 2015, 5709.

[11] For the initial patent: Firmenich, US. Patent 005 219 836A, June 15, 1993. For a stereoselective synthesis: b) E. Brenna, C. Fuganti, S. Ronzani, S. Serra, Can. J. Chem. 2002, 80, 714

[12] D. C. Beshore, A. B. Smith, III, J. Am. Chem. Soc. 2007, 129, 4148

[13] a) J. Chen, C. J. Forsyth, J. Am. Chem. Soc. 2003, 125, 8734; b) J. Chen, C. J. Forsyth, Proc. Nat. Acad. Sci. 2004, 101, 12067; c) D. Ma, B. Zou, G. Cai, X. Hu, J. O. Liu, Chem. Eur. J. 2006, 12,7615 . 